\title{
Effects of Low Estrogens: Vaginal Atrophy
}

\section{PD Gupta}

Former, Director Grade Scientist, Centre for Cellular and Molecular Biology, Hyderabad, India.

Corresponding Author: PD Gupta, Former, Director Grade Scientist, Centre for Cellular and Molecular Biology, Hyderabad, India.

Received date: October 29, 2021; Accepted date: December 06, 2021; Published date: January 03, 2022

Citation: PD Gupta (2022) Effects of Low Estrogens: Vaginal Atrophy. J. Obstetrics Gynecology and Reproductive Sciences 6(1) DOI:10.31579/2578-8965/096

Copyright: @ 2022, PD Gupta, This is an open access article distributed under the Creative Commons Attribution License, which permits unrestricted use, distribution, and reproduction in any medium, provided the original work is properly cited.

\begin{abstract}
Estrogens are the group of hormones which makes a woman a woman. Girls at menarche start making it and under normal conditions sufficient levels are maintained in the women's body until menopause. During perimenopause, menopause and postmenopause the hormone levels start fluctuating and if maintained low for a longer period, it starts giving various problems. Fluctuating levels of estrogen causes, hot flashes, night sweats, vaginal dryness, depression, and mood swings. Sleep disturbances brain fog and may be heart disease, osteoporosis, obesity and the appearance of unwanted facial hair. These problems can be overcome by supplementing with phytoestrogens or hormone replacement therapy.
\end{abstract}

Keywords: estrogens; hormones; menopause

\section{Introduction}

At the time of menarche ovary starts secreting sex steroid hormones viz. estrogens, progesterone which counterbalance each other during the menstruation until menopause [1-4]. The period of menstrual cycle lies in between menarche to menopause in a woman's life. This is the golden period, during this period sex steroids play a major role in regulating physiological processes It is a well-known fact that estrogen is the hormone which makes a woman a woman. Besides making skin look younger due to the secretion of hyaluronic acid, it affects muscle mass, metabolism, and energy levels. Women have more estrogen than men similar to men who have more testosterone than women. New research shows that women whose estrogen level is higher not only look and feel more beautiful, but they behave more sexually aggressively, too. Estrogen has a great impact on a woman's fertility and has been shown to make women dress and behave more provocatively. Besides maintaining the reproductive organs it affects the other organs too such as gingival of women causing them to swell and even bleed [5]. That makes them extra susceptible to plaque and bacteria, increasing the risk for gum disease gingivitis, which if left untreated can result in tooth loss [5]. Because of steroid hormone actions ophthalmic adjustments also takes place in eyes too we have described estrogen receptors in the epithelial cells [6].

\section{Estrogens}

Estrogen are very important chemical compounds essential for our body functions such as, cell proliferation, development and regulation of the female reproductive system; they are primarily responsible for development of secondary sex characteristics $[1,4]$. There are three major endogenous estrogen that have estrogenic hormonal activity namely, estrone (E1), estradiol (E2), and estriol (E3). Estrone, Among
3 estrogenic hormones estradiol is the most important one, produced by granulosa cells of the ovaries. It is responsible for breast development, reproductive health and other female characteristics. It affects pictogram levels. The quantities of this hormone vary due to age, sex, and health history of an individual. In premenopausal females, normal estradiol levels are 30 to $400 \mathrm{pg} / \mathrm{ml}$. In postmenopausal females, normal estradiol levels are 0 to $30 \mathrm{pg} / \mathrm{ml}$. Estrone: comes from the ovaries, as well as the adipose tissue and adrenal glands. It is a weaker estrogen, commonly found in higher quantities in postmenopausal women. Estrone is used in intramuscular and vaginal formulations, and is used as an estrogen in the treatment of symptoms of low estrogen levels such as hot flashes and vaginal atrophy in postmenopausal women. Estrogens are responsible for many of the body's functions, regulating a woman's journey through puberty, fertility and menopause. Estrogen is incredibly important and as we get older production decreases naturally, eventually leading to menopause, characterised by dramatically low levels of estrogen. However, many women will experience hormonal conditions which are caused or exacerbated by estrogen deficiency or an excess (compared to progesterone) in their system.Plants also make estrogenic substances (phytoestrogen); they are very useful for mankind [7].

Synthetic Estrogens: Laboratory made compounds such as, ethiny and diethylstilbesterol, also possess estrogenic activity. These compounds are used in oral contraceptives and as postmenopausal hormone therapy. New data suggest that these exposures induce epigenetic modifications in the mammary gland and germ cells, thereby causing an inheritable increase in breast cancer risk for multiple generations. Maternal exposure during pregnancy increases breast cancer risk in both mothers and their daughters. Estrogen mimicking 
molecules -- Xenoestrogen are a subcategory of the endocrine disruptor which alter the normal function of estrogen $[8,-10]$.

\section{Low estrogen level affects vagina}

Vaginal atrophy: Estrogen helps to keep the vaginal tissue healthy. After menopause, low estrogen levels can cause your vaginal walls to become thin, dry, and inflamed. That often leads to bleeding after sex.At menopause, a woman's estrogen levels can fall by about $85 \%$. Low estrogen levels can impact many aspects of a woman's overall health and wellbeing, including physical, emotional, and sexual health. During menopause, fluctuating levels of estrogen cause symptoms including hot flashes, night sweats, vaginal dryness, depression, and mood swings [14]. Sleep disturbances caused due to menopause appear to contribute to brain fog and may also increase a woman's risk of serious conditions, including heart disease, osteoporosis and obesity [10-12]. As women age, they may notice the appearance of unwanted facial hair. During the hormone changes caused by menopause, estrogen levels decline while levels of testosterone and other androgens rise may be responsible for hair growth on the face as well as excess body hair [12]. Physiologically speaking, estrogen deficiency may cause a decline in serotonin that contributes to mood swings or depression. Increase in urinary tract infections may occur due to the thinning of the tissue in the urethra due to decreased estrogen level. Having the right balance of estrogen is thought to help in maintaining good energy levels implying that low estrogen levels induce a feeling of tiredness. Estrogen regulates glucose and lipid metabolism [13] and low estrogen levels can result in weight gain. Research suggests that this may be why women approaching menopause are likely to become overweight. Overall, depending on the diet, lifestyle, genetics and muscle mass, weight gain or loss could be observed. When the hormone therapy starts, eyes and face will begin to develop a more feminine appearance as the fat under the skin increases and shifts. Vulvovaginal atrophy (VVA) [11], a common and often underreported condition, occurs in women who experience hypo estrogenic states. Vaginal atrophy is when the walls of the vagina get thin, dry, and inflamed due to less estrogen during and after menopause. This condition and its symptoms together are called genitourinary syndrome of menopause (GSM).Vaginal reggae disappear, and the cervix may become flush with the vaginal wall [14]. A vaginal $\mathrm{pH}$ of 4.6 or more supports the diagnosis of VVA. Smoking restricts blood flow, [15] including to the vaginal area as well as lowers the natural amount of estrogen in the body.

Effects of low Estrogens GSM [14] involving both urinary tracts. GSM is observed more in women who haven't had a vaginal birth. Even while taking systemic estrogen, $10 \%$ to $20 \%$ of women may still have residual VVA symptoms. Low estrogen patients suffer also with problems such as vaginal dryness or burning, itching in your genitals, unusual vaginal discharge, more yeast infections, burning during urination, a need to urinate often, a hard time in holding urine (incontinence), more discomfort or bleeding during or after sexual intercourse, less natural lubrication when during sexual intercourse. Up to $40 \%$ of women after menopause have these symptoms however some may have them even during perimenopause. Vaginal dryness is usually the first sign and GSM is common [14].

Causes of Vaginal Atrophy: Vaginal atrophy is when the walls of the vagina get thin, dry and inflamed may be due to less estrogen during and after menopause. Though menopausal phase is the most common reason for GSM [14], the estrogen levels can also go down because of breastfeeding, antiestrogen medications, some birth control pills, surgery to remove both ovaries, chemotherapy, pelvic radiation therapy and hormone treatment. Breast cancer treatment increases the prevalence of VVA due to surgical, endocrine, and chemotherapeutic agents used during the course of the treatment [17]. In the recent past cases of VVA is growing due to decreased use of systemic topical hormone therapy (HT), increased use of selective estrogen receptor modulators (SERMs)(), third-generation aromatase inhibitors (AIs), and chemotherapy in women with a history of breast cancer, for whom the safety of even low-dose vaginal estrogens has not been established [17].

Management of Vaginal Dryness and Pain: There's no reason to be embarrassed if vaginal dryness or pain during sexual intercourse commonly called dyspareunia occurs. That's when the tissue in the vagina gets thinner, less elastic, and tears easily and loses some of the natural lubrication resulting in a "sandpaper" feeling during sexual intercourse. Unlike hot flashes, vaginal dryness won't get better by itself. In fact, the symptoms may get worse without treatment and the vagina may start to itch or feel dry all the time, not just during sex [18]. With less lubrication, the skin around vagina and vulva may burn or itch. Vaginal tissue tearing may lead to bleeding a little after intercourse. One way to ease these problems is to have sex. Those who have regular sexual activity, by themselves or with a partner, tend to have milder cases of vaginal atrophy than those who don't. Sexual activity raises blood flow to the vagina and helps it stay elastic [14]. Vaginal moisturizers or water-based lubricants may help GSM-related dryness and discomfort, especially during sexual activity. Better to use them every few days and just before intercourse. If the problem is not solved better to go for alternate treatment options. Estrogen therapy may be an option to thicken the vaginal walls and ease many of the other symptoms of GSM, too. Estrogen comes in different forms such as creams or suppositories to put into vagina, a soft, flexible ring which the doctor inserts and pills. If dryness, itching, or burning is experienced avoid using perfumes, scented lotion, deodorants, or powders on the pelvic area instead of using unscented soap. Avoid tight clothes, panties, liners and pads which may add to the irritation because of synthetic material. One of the best ways to keep pain away during intercourse is to have regular sexual activity to bump up blood flow and moisture to the vagina.

To help make intimacy more comfortable, a step-by-step approach is better, usually start with the easiest option and go from there. For dryness and atrophy, use of lubricants during sex, vaginal moisturizers, low-dose vaginal estrogen, estrogen-like medicine, vaginal intravaginal dehydroepiandrosterone (DHEA) another hormone, hormone replacement therapy (HRT) may be useful. If muscle or vaginal tightness causes pain, then Pelvic floor therapy or Vaginal dilators may help. Low Libido With ageing, it's normal for sex drive to dip, however, many other situations such as low self-image, stress, relationship issues, depression, or fear of pain during sexual intercourse, lower hormone levels, medication, or poor health conditions could also contribute to low libido. Certain medical conditions can affect blood flow throughout your body including high blood pressure, heart disease, and diabetes. Safe and effective long-term treatments are available now for vaginal dryness or pain with sex. Future research on VVA will likely explore the use of much lower doses of vaginal estrogens, seek to develop newer delivery systems for nonhormonal therapy, and develop SERMs that preferentially target urogenital tissues.

\section{References:}

1. Gupta P D, Lino A, Swarankar Ml. (2000). Mothering a Cause: Practical Knowledge of Reproduction and Motherhood. Oxford \& IBH Publishing Co Pvt Ltd. New Delhi

2. Gupta P D \& Pushkala K. Menarche: (2019)The Essential Event for Motherhood. J Ageing Restor Med, 2(2): 84.

3. Gupta. P D. (2020) Natural and Synthetic Estrogens Regulate Human Health. J Chem Appl. 2: 21-24.2020

4. Gupta P D (2020). Menstrual Cycle and its Importance Arch Reprod Med Sexual Health 3, (2), 51-54.

5. Markou E, Eleana B, Lazaros T, Antonios K. (2009). The influence of sex steroid hormones on gingiva of women. Open Dent J. Jun 5; 3:114-9. 
6. P.D.Gupta Kaid Johar Sr. et al. (2005). Sex Hormone Receptors in the Human Eye Survey of Ophthalmology, Volume 50, Issue 3, May-June Pages 274-284

7. Mackey R Eden,J . (1998). Phytoestrogens Climatric,1,302308.

8. Pamplona Silva MT, Mazzeo DEC, Bianchi J. et al. (2018). Estrogenic Compounds: Chemical Characteristics, Detection Methods, Biological and Environmental Effects. Water Air Soil Pollut 229144

9. Fang H, Tong W, Shi LM, et al. (2001). Structureactivity relationships for a large diverse set of natural, synthetic, and environmental estrogens. Chemical Research in Toxicology. 14: 280-194.

10. Gupta PD, Pushkala K. Parabens: The love - hate molecule. Clin J Obstet Gynecol. (2020); 3: 037-038.

11. Mac Bride MB, Rhodes DJ, Shuster LT. Vulvovaginal atrophy. Mayo Clin Proc. (2010) Jan; 85(1):87-94

12. Lee J, Han Y, Cho HH, Kim MR.(2019). Sleep Disorders and Menopause. J Menopausal Med. 2019 Aug; 25(2):83-87. doi: 10.6118/jmm.19192. Epub Aug 5. Erratum in: J Menopausal Med. 2019 Dec; 25(3):172.

13. Grymowicz M, Rudnicka E, Podfigurna A, Napierala P, Smolarczyk R, Smolarczyk K, Meczekalski B. (2020) Hormonal Effects on Hair Follicles. Int J Mol Sci. Jul 28; 21(15):5342.

14. Mauvais-Jarvis F, Clegg DJ, Hevener AL. (2013). The role of estrogens in control of energy balance and glucose homeostasis. Endocr Rev. 2013 Jun; 34(3):309-38.

15. Gupta, P.D. and Pushkala, K (2005). Human syndromes. Oxford \& IBH Publishing, New Delhi-India 2005

16. Mueck AO, Seeger H. (2005). Smoking, estradiol metabolism and hormone replacement therapy. Curr Med Chem Cardiovasc Hematol Agents. Jan; 3(1):45-54.

17. Robinson D, Toozs-Hobson P, Cardozo L. (2013). The effect of hormones on the lower urinary tract. Menopause Int. Dec;19(4):155-62

18. Abrams JS, Moore TD, Friedman M. (1994). New chemotherapeutic agents for breast cancer. Cancer. Aug 1;74(3 Suppl): 1164-76

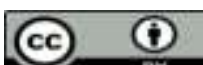

This work is licensed under Creative Commons Attribution 4.0 License

To Submit Your Article Click Here:

Submit Manuscript
Ready to submit your research? Choose Auctores and benefit from:

* fast, convenient online submission

* rigorous peer review by experienced research in your field

* rapid publication on acceptance

* authors retain copyrights

* unique DOI for all articles

* immediate, unrestricted online access

At Auctores, research is always in progress.

Learn for more auctoresonline.org/journals/obstetrics-gynecology-andreproductive-sciences- 